\title{
The Correlation of Hospital Operational Efficiency and Average Length of Stay in China: A Study Based on Provincial Level Data
}

\author{
Qian Liu' ${ }^{*}$, Xinyu Zhang1*, Yanan Guo1, Yao Zhang1, Yaxuan Wang1, Bo Li², Yaogang Wang1\# \\ ${ }^{1}$ School of Public Health, Tianjin Medical University, Tianjin, China \\ ${ }^{2}$ International College of Business and Technology, Tianjin University of Technology, Tianjin, China \\ Email: "wangyg@tmu.edu.cn
}

How to cite this paper: Liu, Q., Zhang, X.Y., Guo, Y.N., Zhang, Y., Wang, Y.X., Li, B. and Wang, Y.G. (2016) The Correlation of Hospital Operational Efficiency and Average Length of Stay in China: A Study Based on Provincial Level Data. Journal of Biosciences and Medicines, 4, 49-55. http://dx.doi.org/10.4236/jbm.2016.412008

Received: October 20, 2016 Accepted: November 24, 2016 Published: December 1, 2016

\begin{abstract}
Objective: To measure the hospital operation efficiency, study the correlation between average length of stay and hospital operation efficiency, analyze the importance of shortening average length of stay to the improvement of the hospital operation efficiency and put forward relevant policy suggestion. Methods: Based on China provincial panel data from 2003 to 2012, the hospital operation efficiencies are calculated using Super Efficiency Data Envelopment Analysis model, and the correlation between average length of stay and hospital operation efficiency is tested using Spearman rank correlation coefficient test. Results: From 2003 to 2012, the average of national hospital operation efficiency was increasing slowly and the hospital operations were inefficient in most of the areas. The national hospital operation efficiency is negatively correlated to the average length of stay. Conclusion: Measures should be taken to set average length of stay in a scientific and reasonable way, improve social and economic benefits based on the improvement of efficiency.
\end{abstract}

\section{Keywords}

Average Length of Stay, Hospital Operation Efficiency, Correlation, Super Efficiency Data Envelopment Analysis

\section{Introduction}

At present, the key to solving the problem of the imbalance between supply and de-

${ }^{\star}$ Qian Liu and Xinyu Zhang are co-first authors and contributed equally to this work. 
mand in the field of medical service is to improve the operational efficiency of the hospital, so as to effectively improve the capacity of medical and health services. Average length of stay has been considered as an important indicator in the assessment of medical care and health service performance. Average length of stay (ALOS) refers to average number of days staying in hospital for every inpatient within a certain period of time (usually one year). Various measures have been taken to reduce average length of stay to improve medical care and health service efficiency in different countries. To reasonably shorten the average length of stay is of great significance in easing the pressure on medical beds and optimizing the allocation of health resources because it will not only alleviate the medical expenditure burden on patients, but will also expand the patient reception capacity for hospitals, thus contributing to the improvement of social welfare and economic benefits. The existing literatures focus more on measuring the hospital efficiency using Data Envelopment Analysis [1]-[4]. Some other the previous studies studied the length of stay [5] [6]. However, much less attention has been paid to the relationship between operational efficiency and average length of stay in hospital. This paper quantitatively investigates the relationship between average length of day and operational efficiency in hospital in order to provide feasible policy reference for the optimization of hospital medical resource allocation in China.

\section{Data and Methods}

\subsection{Data Sources}

The data used in this paper is extracted from the OECD (Organization for Economic Cooperation and Development) database (2004-2013), and China Health Statistical Yearbook (2004-2013). According to the statistical caliber of China health Statistical Yearbook, the term "hospital" in this paper refers to general hospital, hospital of traditional Chinese medicine, integrated hospital of traditional Chinese and western medicine, national hospital, and all kinds of specialized hospitals and nursing homes, but not includes specialized disease control center, maternal and child care service center and convalescent hospital.

\subsection{Research Method}

First, this paper analyzes the changing trends of average length of stay in different countries including the United States, Australia, United Kingdom, Chile from 2003 to 2012. Second, this paper uses the Super-Efficiency DEA model and selects the data of the number of hospitals, hospital medical beds and the number of health personnel in 31 provinces of China from 2003 to 2012 as input variables, and chooses hospital visits of outpatient and emergency department, number of inpatients, number of discharged patients, and the number of surgeries of hospital inpatients as output variables. Use these methods and data, this paper measures the hospital operational efficiency in each province and studies the correlation between efficiency and average length of stay. 


\section{Results}

\subsection{Comparative Analysis of Length of Stay among Domestic and Foreign Hospitals}

Average length of stay of the discharged inpatients from hospital is an indicator reflecting the hospital operational efficiency and service performance. The decrease of average hospital length of stay indicates the improvement of the comprehensive efficiency of the hospital. Shortening average length of stay within reasonable limits will not only reduce the medical expenditure burden on patients, but will also improve the utilization rate of hospital medical bed so as to meet medical health needs of more patients.

As can be seen from Figure 1, from 2003 to 2012, there exists a declining trend in the average lengths of stay of the discharged inpatients from hospital in five countries. In China, the average length of stay declines from 11 days to 10 days. Although the declining degree is moderate for those countries, the general trend is the decrease of average length of stay annually, which indicates that each of the countries is actively optimizing resource utilization to improve efficiency and reduce the average length of stay as much and reasonable as possible. The largest decline happens in the United Kingdom, a reduction of 2.4 days. Although has been decreased, the average length of stay in China is still the largest in the five countries.

\subsection{Measurement of Hospital Operational Efficiency in China}

Using Super-Efficiency DEA model, the hospital operational efficiencies of 31 provinces in China from 2003 to 2012 are calculated. The results are shown in Table 1.

Due to space limitation, only the values of hospital operational efficiencies of 31 provinces in 2003 and 2012, and 10-year average efficiencies are listed in Table 1. As can be seen from Table 1, based on the comparison of provincial hospital operational

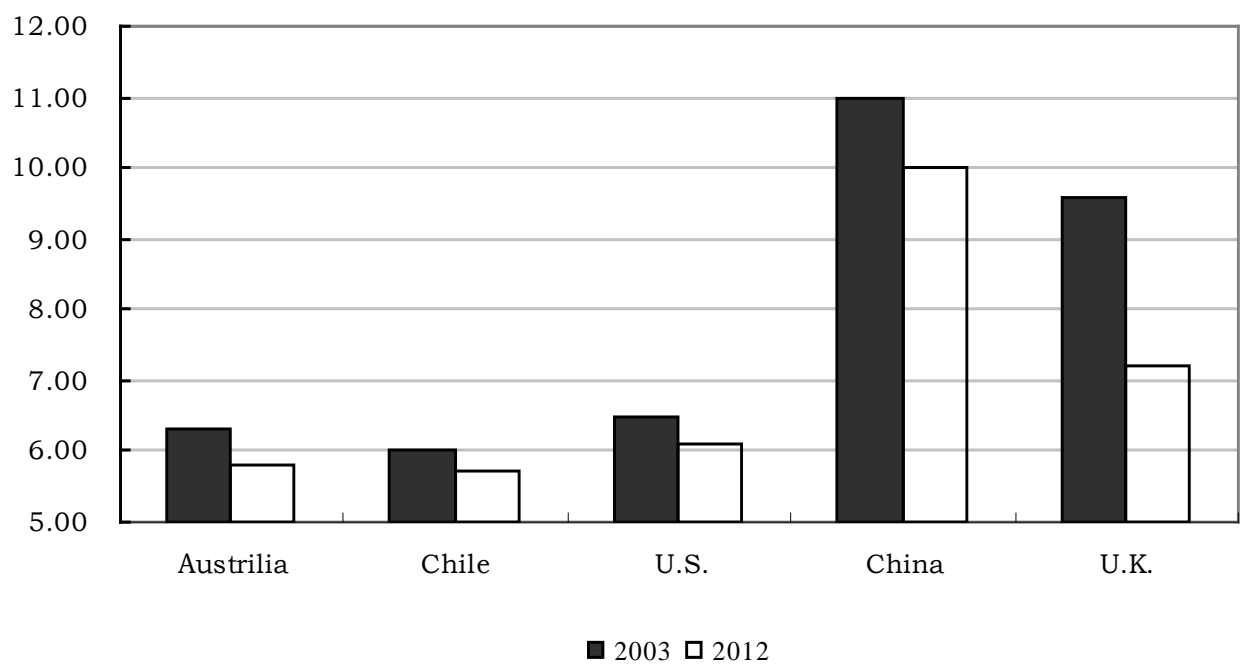

Figure 1. Average length of stay of the discharged inpatients from hospital in five countries from 2003-2012. 
efficiencies between 2003 and 2012, the efficiencies in only 6 provinces are improved. From the perspective of 10 -year average efficiencies, the hospitals only 5 provinces are generally in efficient status.

\subsection{Normality Test of Hospital Operational Efficiency and Average Length of Stay}

Based on the result of single sample Kolmogorov-Smirnov test, as shown in Table 2,

Table 1. Hospital operational efficiencies in 31 provinces of China.

\begin{tabular}{cccccccc}
\hline Province & 2003 & $\mathbf{2 0 1 2}$ & $\begin{array}{c}\mathbf{2 0 0 3 - 2 0 1 2} \\
\text { average }\end{array}$ & Province & 2003 & 2012 & $\begin{array}{c}\text { 2003-2012 } \\
\text { average }\end{array}$ \\
\hline Beijing & 0.6546 & 0.5994 & 0.7789 & Hubei & 0.8783 & 0.7506 & 0.9604 \\
Tianjin & 0.5799 & 0.5538 & 0.7268 & Hunan & 0.8163 & 0.8063 & 0.9205 \\
Hebei & 0.8544 & 0.7870 & 0.8846 & Guangdong & 1.3095 & 1.3663 & 1.2667 \\
Shanxi & 0.6010 & 0.5822 & 0.6052 & Guangxi & 0.9297 & 0.8749 & 0.9602 \\
Inner Mongolia & 0.6717 & 0.6113 & 0.6862 & Hainan & 0.7667 & 0.7430 & 0.8132 \\
Liaoning & 0.6230 & 0.6145 & 0.6809 & Chongqing & 0.8625 & 0.8953 & 0.9079 \\
Jilin & 0.6392 & 0.6163 & 0.6833 & Sichuan & 0.9143 & 0.9053 & 0.9435 \\
Heilongjiang & 0.6599 & 0.6178 & 0.6691 & Guizhou & 0.8281 & 0.9331 & 0.9169 \\
Shanghai & 1.3420 & 1.4164 & 1.3624 & Yunnan & 0.9006 & 0.8653 & 1.0404 \\
Jiangsu & 0.9617 & 0.8742 & 0.9174 & Tibet & 0.5076 & 0.4493 & 0.6149 \\
Zhejiang & 1.1422 & 1.3862 & 1.0564 & Shaanxi & 0.7202 & 0.6527 & 0.7694 \\
Anhui & 0.8552 & 0.8012 & 0.8994 & Gansu & 0.6722 & 0.6749 & 0.7670 \\
Fujian & 1.1036 & 1.0325 & 1.0934 & Qinghai & 0.8296 & 0.6862 & 0.7646 \\
Jiangxi & 0.9264 & 0.8090 & 0.9478 & Ningxia & 0.7702 & 0.7563 & 0.8111 \\
Shandong & 0.9418 & 0.9280 & 0.9122 & Xinjiang & 0.9013 & 0.8990 & 0.9248 \\
Henan & 0.8197 & 0.7905 & 0.8568 & - & - & - & - \\
\hline
\end{tabular}

Table 2. Kolmogorov-Smirnov test results.

\begin{tabular}{cccc}
\hline \multicolumn{1}{c}{$\mathrm{N}$} & \multicolumn{2}{c}{ ALOS } & Efficiency \\
\hline \multirow{2}{*}{ Normal parameters $^{\mathrm{a}}$} & Mean & 310 & 310 \\
& Std. Deviation & 10.8826 & 0.8755 \\
& Absolute & 0.170 & 0.18474 \\
Most extreme differences & Positive & 0.170 & 0.093 \\
& Negative & -0.099 & -0.044 \\
Kolmogorov-Smirnov Z & & 2.999 & 1.636 \\
Asymp. Sig. (2-tailed) & & 0.000 & 0.009
\end{tabular}

${ }^{\mathrm{a}}$ Test distribution is normal. 
p-values of hospital operational efficiency and average length of stay are both smaller than 0.05 , which means that both of the data arrays don't obey normal distribution. Therefore, it is necessary to use Spearman rank correlation coefficient to test the correlations between hospital operational efficiency and average length of stay.

\subsection{Correlation Analysis of Hospital Operational Efficiency and Average Length of Stay}

Using Spearman rank correlation coefficient, the correlation of hospital operational efficiency and average length of stay is tested. The results are shown in Table 3. From the table, it is clear that there exists significant negative correlation between hospital operational efficiency and average length of stay, which means that the shortening of average length of stay could significantly improve the hospital operational efficiency in China.

\section{Discussions}

\subsection{Shrink the Difference of Average Length of Stay between China and Other Countries}

Through comparison it is clear that even if health resources are relatively abundant, the average length of stay in each country should be reduced to optimize the utilization efficiency of the medical bed, so as to maximize the utilization of limited resources to meet the needs of patients. The main reasons to the differences of average length of stay across different countries mainly due to the following three aspects: 1) the wasting of relatively scarce medical care and health service resources; 2) Shortage of nursing personnel; 3) Inadequate primary medical care system.

\subsection{Reasonably Set Average Length of Stay to Improve the Social and Economic Benefits by Efficiency Improvement}

The results show that Chinese hospital operating efficiency and the average length of stay were significantly negatively correlated. Shortening the average length of stay will help patients get timely treatment, reduce the chance of repeated infection and reduce the medical expense burdens on patients, facilitate more reasonable resource configuration, and accelerate the turnover rate of hospital medical beds, so as to increase the

Table 3. Correlation test results.

\begin{tabular}{cccc}
\hline & & ALOS & Efficiency \\
\hline \multirow{2}{*}{ ALOS } & Correlation coefficient & 1.000 & $-0.336^{* *}$ \\
& Sig. (2-tailed) & $\cdot$ & 0.000 \\
& $\mathrm{~N}$ & 310 & 310 \\
Efficiency & Correlation coefficient & $-0.336^{* *}$ & 1.000 \\
& Sig. (2-tailed) & 0.000 & $\cdot$ \\
& $\mathrm{N}$ & 310 & 310 \\
\hline
\end{tabular}


number of visits and further enhance medical income. In the mean time, the social and economic benefits of hospital could be improved [7].

\subsection{Shorten the Ineffective Length of Stay, and Improve the Hospital Operational Efficiency}

In order to shorten the average length of stay, it is important to reduce the ineffective length of stay in the hospital which not only increases the economic burden on patients and their families, but also wastes scarce medical resources and reduces medical income of hospitals. Therefore, in order to improve hospital operational efficiency and shorten average length of stay, it is of great importance to sharply reduce or erase ineffective length of stay, which requires the improvement of management level and medical skill and technology levels, together with the cooperation and coordination among inpatient department and other hospital departments, and the active involvement of every health technical personnel. At the same time, two-way referral mechanism should be further improved [8], which requires that the hospital inpatients in rehabilitation period and inpatients with chronic disease should be discharged in time or transferred to primary health service center to receive follow-up rehabilitation treatment.

\section{Funding}

This study was supported by the National Natural Science Foundation of China [No. 71273187] and National Natural Science Foundation of China [No. 71473175].

\section{References}

[1] Pan, J.X., Wang, X.W. and Li, J. (2014) Empirical Analysis on the Efficiency of Second Level Hospital and the Influencing Factors: Based on the Investigation Analysis of 14 General Hospitals of a Region. Chinese Health Economics, 33, 84-87.

[2] Mao, Y.N., Wang, X.W., Feng, R.H. and Cui, Y.Y. (2015) Study on Screening Hospital Efficiency Evaluation Index Based on DEA. Health Economics Research, 8, 15-19.

[3] Saronga, H.P., Duysburgh, E., Massawe, S., Dalaba, M.A., Savadogo, G., Tonchev, P., et al. (2014) Efficiency of Antenatal Care and Childbirth Services in Selected Primary Health Care Facilities in Rural Tanzania: A Cross-Sectional Study. BMC Health Services Research, 14, 96. http://dx.doi.org/10.1186/1472-6963-14-96

[4] Zhang, X., Zhao, L., Cui, Z. and Wang, Y. (2015) Study on Equity and Efficiency of Health Resources and Services Based on Key Indicators in China. PLOS ONE, 10, e0144809. http://dx.doi.org/10.1371/journal.pone.0144809

[5] Subbe, C.P., Kellett, J., Whitaker, C.J., et al. (2014) A Pragmatic Triage System to Reduce Length of Stay in Medical Emergency Admission: Feasibility Study and Health Economic Analysis. European Journal of Internal Medicine, 25, 815-820. http://dx.doi.org/10.1016/j.ejim.2014.06.001

[6] Xiao, Q., Wu, X.M., Zhou, W.G., Yang, R.C., Chen, H.X., Ji, AD. and Xiao, Y.H. (2015) Correlation Analysis of Hospitalization Cost and Length of Hospital Stay among Urban and Rural Medicare-Insured and -Participating Residents. Modern Preventive Medicine, 42, 652-654.

[7] Li, Y.W. (2014) Discussion on the Method of Shortening Average Length of Stay. Journal of 
Traditional Chinese Medicine Management, 2, 295-296.

http://dx.doi.org/10.1186/s12967-014-0295-x

[8] Yi, L.H., Huang, P., Jiang, S.Q., Hao, A.M., Zhao, X., Qu, S., Han, Z.J., Xing, M., Ding, L.H., Lin, J., Xu, X.Z. and Yang, X.L. (2015) Analysis on the Two-Way Referral by Leading Hospitals of Three Health Alliances. Chinese Journal of Hospital Administration, 31, 253-257.

Submit or recommend next manuscript to SCIRP and we will provide best service for you:

Accepting pre-submission inquiries through Email, Facebook, LinkedIn, Twitter, etc. A wide selection of journals (inclusive of 9 subjects, more than 200 journals)

Providing 24-hour high-quality service

User-friendly online submission system

Fair and swift peer-review system

Efficient typesetting and proofreading procedure

Display of the result of downloads and visits, as well as the number of cited articles

Maximum dissemination of your research work

Submit your manuscript at: http://papersubmission.scirp.org/

Or contact jbm@scirp.org 